\title{
Étude in vitro des réactions hémocytaires d'Invertébrés et de leur sensibilité à certaines influences biochimiques
}

\author{
par A. VEY \\ Station de Recherches de Cytopathologie, I.N.R.A.-C.N.R.S., F 30380 Saint-Christol
}

Les réactions hémocytaires des Invertébrés ont le plus souvent été étudiées chez l'hôte, bien qu'il soit difficile dans ces conditions de suivre leur dynamique. L'expérimentation in vitro peut par contre permettre une observation continue des processus. Elle est également favorable à la mise en évidence de leur sensibilité à certains facteurs chimiques, physiologiques ou microbiens. C'est dans cette perspective que nous avons cherché à reproduire les réactions hémocytaires in vitro en faisant appel aux milieux et aux techniques de la culture de cellules d'Invertébrés.

En mettant en présence des hémocytes du Lépidoptère Galleria mellonella et des spores de plusieurs espèces d'Aspergillus, nous avons obtenu pour la première fois la réaction de granulome hors de l'organisme de l'hôte. Dans les préparations, confectionnées en lames creuses ou calibrées, le déroulement de la réaction a pu être suivi pendant 36 heures (Vey, Quiot, Vago, 1968; Vey, 1969).

Pour analyser avec plus de précision les réactions hémocytaires, nous avons associé la technique d'expérimentation in vitro avec la microcinématographie image par image. Pour ces expériences, nous avons employé des hémocytes des mollusques Helix aspersa et Zonites sp., et des éléments du champignon Metarrhizium anisopliae ou de la bactérie Streptococcus faecalis (Vago, 1963: Vago et Vey, 1972).

Le processus d'endocytose se réalise in vitro par des voies différentes en fonction de la taille, de la forme et du mode de groupement des microorganismes (Vey et al., 1975) :

— Etablissement d'un contact étroit entre la cellule et l'agent étranger, qui est ensuite happé à l'intérieur du cytoplasme. 
- Encerclement puis incorporation des germes grâce à un ou des pseudopodes effectuant des mouvements importants.

- Incorporation d'éléments fongiques de grande taille. Dans ce cas, la cellule s'allonge en contact étroit avec le fragment mycélium, le replie au moyen de mouvements de contraction, et parvient finalement à l'englober en totalité. Une vacuole phagocytaire peut apparaître après l'incorporation. La durée totale de ce processus atteint trois à quatre heures. La cellule qui reste en place pendant le déroulement de la réaction reprend ensuite sa forme normale et ses déplacements.

Nous avons également analysé la réaction de granulome (Vey et al., 1975). Une puis plusieurs cellules adhèrent au filament. D'autres hémocytes se déplaçant très activement viennent se joindre à elles, parfois par groupes entiers, et se serrent les uns contre les autres. Sur cet agglomérat viennent se fixer de nouveaux hémocytes qui se rétractent et s'incorporent à la surface du granulome en formation en montrant des mouvements vigoureux et en émettant puis rétractant à un rythme rapide des petits bourgeons arrondis (processus de «bubbling »). L'arrivée de nouvelles cellules se ralentit, puis s'arrête. Les granulomes se présentent alors comme des masses subsphériques de 0,2-0,4 $\mathrm{mm}$ de diamètre qui ont à leur périphérie une frange de courts pseudopodes. Il n'a pas été possible de déterminer si le premier contact hémocyte-élément mycélien résulte d'une attraction; par contre, les cellules déjà groupées autour du champignon attirent nettement celles se trouvant dans leur voisinage.

Pour étudier l'effet de certains facteurs sur les réactions hémocytaires, nous avons mis au point une méthode de reproduction de la réaction de granulome permettant de suivre son déroulement pendant trois à quatre jours et d'obtenir de volumineux groupements hémocytaires. Nous avons utilisé les hémocytes du Coléoptère Oryctes rhinoceros, les conidiospores de $M$. anisopliae partiellement inactivées servant de stimulus.

Nous avons testé l'effet sur la réaction obtenue d'une source brute de toxines constituée par du filtrat culture de Metarrhizium dilué (Vey et Quiot, 1975). Ce filtrat a une action cytotoxique importante sur les hémocytes de l'hôte. Dans les cultures renfermant à la fois des spores et des substances toxiques, les cellules se fixent normalement au cours des premières heures, mais après dix heures le rassemblement hémocytaire déjà perceptible en l'absence de filtrat ne s'amorce pas. Les cellules s'altèrent de plus en plus, et même après 2 ou 3 jours, aucun groupement hémocytaire ne se produit.

Grâce à une méthode de reproduction in vitro, nous avons ainsi pu mettre en évidence l'effet inhibiteur de toxines fongiques sur la réaction de granulome. Des recherches faisant appel à ce type de méthode sont actuellement en cours pour définir l'action de diverses substances d'origine microbienne, d'hormones, et d'anti-inflammatoires sur les mécanismes de défense hémocytaire. L'association des techniques d'obtention in vitro des réactions cellulaires avec la microcinématographie s'avérerait certainement très favorable pour l'étude de l'influence de ces facteurs, ainsi que pour des investigations concernant l'aspect phylogénétique des réactions. 


\section{Bibliographie}

VAGo (C.), 1963. - Culture de cellules de tissus d'Invertébrés. Film (Service Français Film Recherche Scientifique).

VAGo (C.) et VeY (A.), 1972. - Mycoses d'Invertébrés. Film (Service Français Film Recherche Scientifique).

VEY (A.), 1969. - Etude in vitro des réactions hémocytaires anticryptogamiques des larves de Lépidoptères. Ann. Zool. Ecol, animale, 1, n h.-sér., 93-100.

VeY (A.) et Quiot (J.-M.), 1975. - Effet in vitro de substances toxiques produites par le champignon Metarrhizium anisopliae (Metsch.), Sorok. sur la réaction hémocytaire du Coléoptère Oryctes rhinoceros L. C.R. Acad. Sci., D, 280, 931-934.

VeY (A.), Quiot (J.-M.) et VAGo (C.), 1968. - Formation in vitro de réactions d'immunité cellulaire chez les insectes. Proc. 2nd Intern. Coll. Invert. Tissue Cult, 254-263, 254-263.

Vey (A.), Bouletreau (M.), Quiot (J.-M.) et VAGo (C.), 1975. - Etude in vitro en microcinématographie des réactions cellulaires d'Invertébrés vis-à-vis d'agents bactériens et cryptogamiques. Entomophaga, 20, 337-351. 